\section{Designed with infection control in mind}

Maintaining a safe, clean environment is essential for every practice. With many patients to see and treat everyday, you need a dental unit designed with infection control in mind.

The Skema 8 from Castellini meets the strictest infection control requirements to ensure that both you and your patients are not put at any unnecessary risk.

The Skema 8 is easy to clean and disinfect with removable components such as upholstery, footrest and handles to make hygienic applications easier and more effective. The Skema 8 also features a highly advanced, large touch screen display made of tempered glass, which can be completely sanitised.

The Skema 8 is a complete treatment centre with integrated instruments that can be easily dissembled and autoclaved to optimise decontamination procedures. There is also quick and easy access to the disinfectant tank and dental unit body.

Make it easy for you and your team to comply with regulations and ensure the safety of your patients by contacting Castellini for more details today. Call 08000933975 and speak to Castellini UK directly for assistance.

\title{
Outstanding clarity with a small footprint
}

With its small footprint, the CS 8100 family of compact 2D, 3D and cephalometric systems from Carestream Dental is designed to make your life easier.

Whether you seek panoramic, cephalometric or 3D imaging, or would like access to a combination of tools, the CS 8100, CS 8100SC and CS 8100 3D will meet your needs.

All units deliver images of outstanding clarity for highly accurate and reliable diagnostics and treatment planning, as well as enhanced communication with the patient and the laboratory. Featuring intuitive interfaces, fast image capture and simple integration within your existing technologies, all CS 8100 systems facilitate an easy workflow for the whole team.

What's more, their small sizes ensure they easily fit in even the tightest of spaces within your practice for maximum convenience.

Size really does matter - discover the CS 8100 family from Carestream Dental today on 08001699692 or visit www.carestreamdental.co.uk.

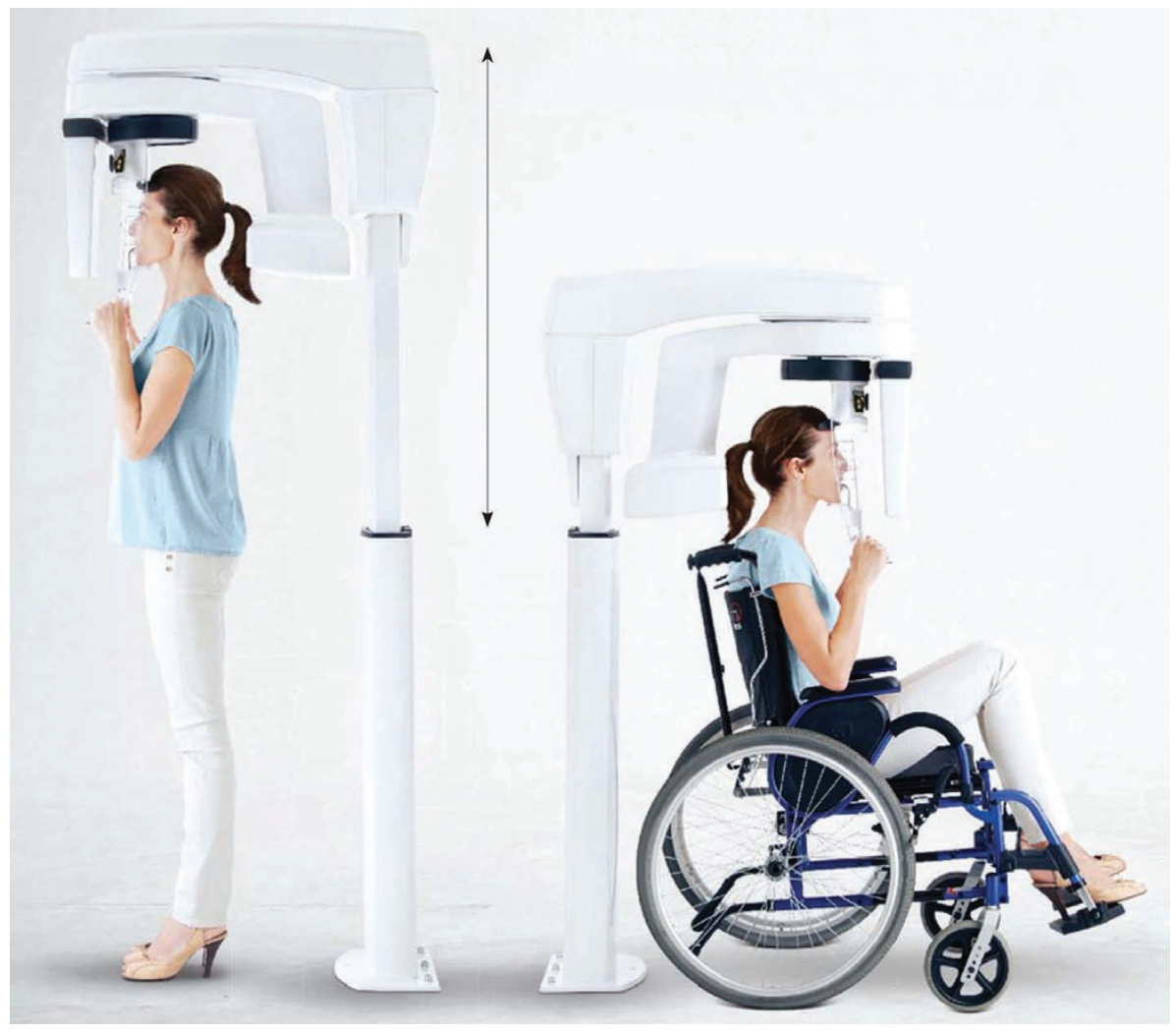

\section{Exciting changes in store}

The Association of Dental Groups (ADG) is excited to announce that the Bursary Awards will be undergoing a makeover moving forward into 2018.

As of next year, the ADG will be introducing a new classification in the undergraduate category entitled 'Innovation in Dentistry'. This will encompass the concept of skills mix whilst encouraging other ideas as to how the delivery of dentistry should develop. The undergraduate 'Professionalism' category and the postgraduate award will remain the same.

As for the presentation of the awards, the prestigious ceremony is due to take place later on in the year, with the deadline expected to move forward as well for hopeful students wishing to apply.

If you or someone you know is interested in applying for either the undergraduate of postgraduate Bursary Awards, go online to find out more today.

For more information about the ADG visit www.dentalgroups.co.uk.

\section{Do you have a colleague who needs support?}

Do you know a colleague who is struggling with mental health issues, problems with alcohol, drugs or an eating disorder? The Dentists' Health Support Trust can help. For confidential professional treatment and advice, call 02072244671 or visit www. dentistshealthsupporttrust.org .

The Dentists' Health Support Trust can provide:

- Advice and counselling from a mental health professional

- Treatment programme individually designed

- Inpatient treatment when appropriate

- Support and advice for friends, family and colleagues

- Assistance to return to work and support during recovery.

The Dentists' Health Support Trust is a charity and entirely supported by donations. It is run by dentists for dentists. Charity number: 1003819. 